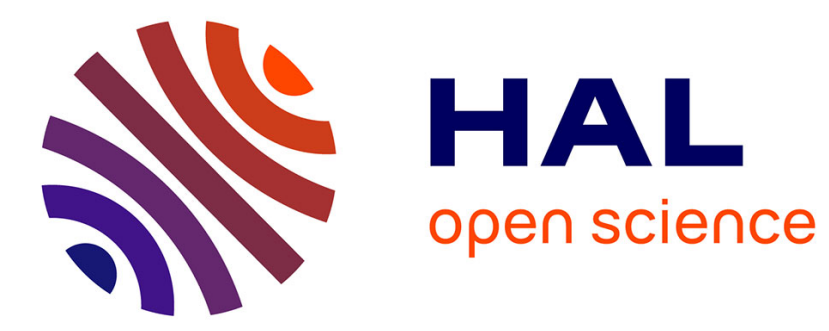

\title{
Revealing surface functionalities via microwave for the para-fluoro-Thiol click reaction
}

Coste Mawélé Loudy, Sirikorn Chasvised, Clara Paybou, Cecile Courreges, Joachim Allouche, Hervé Martinez, Antoine Bousquet, Laurent Billon

\section{- To cite this version:}

Coste Mawélé Loudy, Sirikorn Chasvised, Clara Paybou, Cecile Courreges, Joachim Allouche, et al.. Revealing surface functionalities via microwave for the para-fluoro-Thiol click reaction. Polymer, 2020, 202, pp.122675. 10.1016/j.polymer.2020.122675 . hal-02911028

\section{HAL Id: hal-02911028 \\ https://hal-univ-pau.archives-ouvertes.fr/hal-02911028}

Submitted on 9 Nov 2020

HAL is a multi-disciplinary open access archive for the deposit and dissemination of scientific research documents, whether they are published or not. The documents may come from teaching and research institutions in France or abroad, or from public or private research centers.
L'archive ouverte pluridisciplinaire HAL, est destinée au dépôt et à la diffusion de documents scientifiques de niveau recherche, publiés ou non, émanant des établissements d'enseignement et de recherche français ou étrangers, des laboratoires publics ou privés. 
Revealing Surface Functionalities via Microwave for the para-Fluoro-Thiol Click

\section{Reaction}

Coste Mawélé Loudy ${ }^{a}$, Sirikorn Chasvised ${ }^{\mathrm{a}}$, Clara Paybou $^{\mathrm{a}}$, Cécile Courrèges ${ }^{\mathrm{a}}$, Joachim Allouche ${ }^{\mathrm{a}}$, Hervé Martinez $^{\mathrm{a}}$, Antoine Bousquet*a, Laurent Billon ${ }^{\mathrm{a}, \mathrm{b}}$

${ }^{a}$ CNRS/ Univ Pau \& Pays Adour/ E2S UPPA, Institut des Sciences Analytiques et de Physicochimie pour l'Environnement et les Matériaux, UMR 5254, 64000, PAU, France

${ }^{b}$ Bio-inspired Materials Group: Functionality \& Self-assembly, Université de Pau et des Pays de l'Adour, IPREM CNRS-UMR 5254, 64000, PAU, France

"for Table of Contents use only"
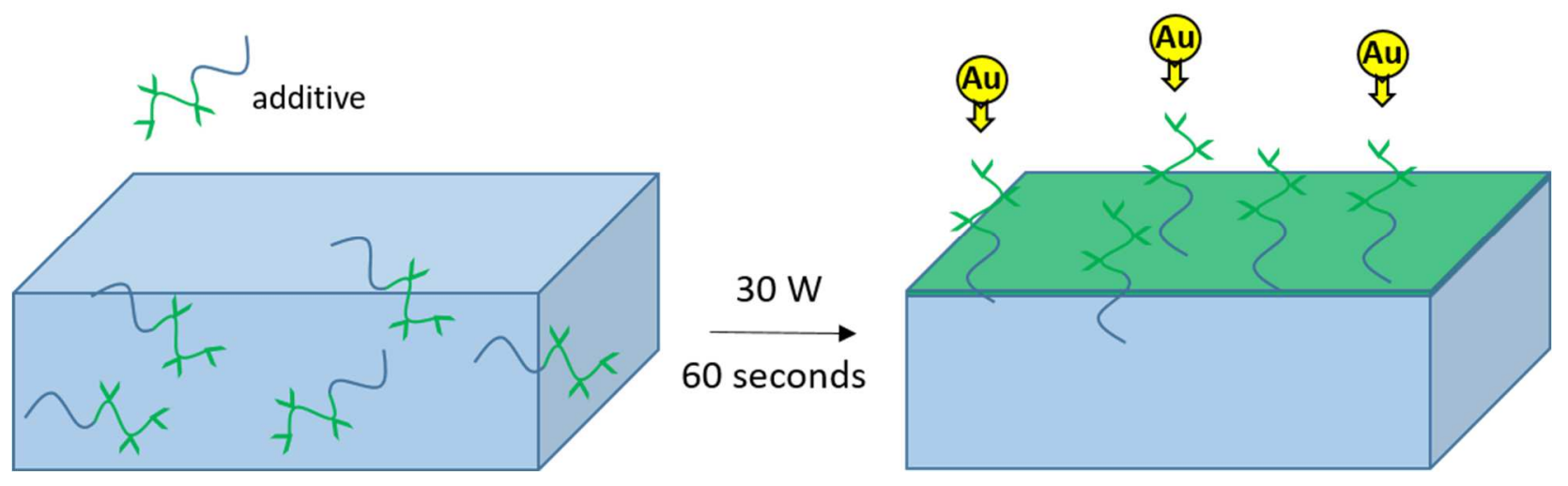


\begin{abstract}
:
A fast and simple bottom-up methodology is reported to allow, thanks to a spontaneous phenomenon, the grafting of various materials on polymer substrates. In 60 seconds, the inert surface of polystyrene material is converted into a functional platform onto which organic molecules and metal particles can be anchored. A polystyrene (PS) matrix is blended with a small amount of a diblock copolymer additive engineered to both segregate at the material surface and be able to involve chemical reaction. Indeed, poly(penta fluorostyrene) (PSF) contains surface active fluorine atoms and the nucleophuge para-fluorine atom that allow nucleophilic substitution with thiols. Films of blend of PS matrix and PS- $b$-PSF additive are submitted to a microwave annealing to accelerate the spontaneous surface segregation of fluorine low surface energy atoms. XPS was performed to find that the optimal annealing condition was a treatment at $30 \mathrm{~W}$ during 60 seconds. With this procedure, a blend of $5 \mathrm{w} \%$ in additive can lead to a surface composed of 13 at $\%$ of fluorine atoms corresponding to $55 \mathrm{w} \%$ of diblock. The pentafluorostyrene units decorating the surface were used as anchors to immobilize gold nanoparticles via the para-fluoro-thiol click reaction.
\end{abstract}

Keywords: para-fluoro-thiol click reaction, surface segregation, diblock copolymer, microwave, gold nanoparticles.

\title{
1. Introduction
}

The control of surface composition and properties, such as wettability, adhesion, biocompatibility, friction and wear, is crucial to develop applications in electronics, water-treatment, energy and biomedical industries.[1-5]. Efficient "click chemistry" reactions have been developed for 30 years to graft surfaces with molecules, macromolecules, metal or inorganic nanoparticles.[6] Among them, Huisgen cycloaddition[7, 8], thiol-ene reaction[9], or Diels-Alder cycloadditions[10] are the most used. Recently, a new reaction has been investigated by the community: the nucleophilic aromatic substitution of para-fluorine atom of pentafluorophenyl moeities by a variety of nucleophiles, such as thiols, amines and alcohols.[11] The main limitation of these "click" methodologies is that the substrate must present surface reactive functions for the grafting to happen. Therefore, it is limited to a small range of materials. 
Polymers surface modification is a powerful tool in order to allow cheap inert materials to gain reactive surface functionalities. Surface segregation, a spontaneous phenomenon based on thermodynamics, is a "soft" way of modifying the external properties of a materials blend. It is directed by the equilibrium between the decrease of surface tension and the energy cost of segregation from the bulk, as governed by Gibbs adsorption isotherm.[12, 13] Therefore, in a polymer blend, a "surface field" drives the migration of the material with the lowest surface tension to the air interface. As a consequence, the phenomenon leads to significant modifications between the surface and the bulk composition and properties.[14-16] Surface segregation has been demonstrated in several polymeric systems[17-21], either in flat[22] or spherical[23] material and in dry (vacuum) or humid environment[24].

Even if surface segregation is a spontaneous phenomenon, the thermic properties of the blends components have a huge influence on the process kinetics. Blends of polystyrene (PS) and end-functionalized polystyrene, which glass transition temperatures $\left(T_{g}\right)$ are around $100^{\circ} \mathrm{C}$, would reach thermal equilibrium in the time scale of weeks at room temperature. A thermal annealing above $T_{g}$ is required to reduce the segregation time to half a day.[25] Perhaps the most reported system is the blend of an end-fluorinated polystyrene additive (PS-F) in a PS matrix.[25-29] In the publications, the authors showed a strong fluorine surface enrichment and very hydrophobic films were produced. Indeed, the material surface energy is reduced by the segregation of fluorine atoms having a lower surface tension than the styrene repetitive units. In 1994, Affrossman et al. used PS-F/PS blend, they showed that an initial weight composition of $15 / 85$, after a thermal annealing at $130^{\circ} \mathrm{C}$ for 24 hours, could lead to an enrichment in PS-F of $62 \mathrm{w} \%$. Elman and coworkers proved by neutron reflectivity the segregation of deuterated PS-F in a hydrogenated polystyrene matrix.[25] Other studies were published [26, 28, 29], confirming the segregation of fluorinated polymers after annealing above $\operatorname{Tg}$ (from $110^{\circ} \mathrm{C}$ to $165^{\circ} \mathrm{C}$ ) in the time scale of days (from $12 \mathrm{~h}$ to $72 \mathrm{hrs}$ ).

Nowadays, energy is a vital challenge for mankind and many research studies are devoted to reduce its consumption. In this report, a rapid method is described to perform the fluorine surface enrichment in sixty seconds, thus dividing the annealing time by 1440 ( 1 day/1minute). Microwave-induced annealing is used to allow the surface segregation of a fluorinated additive in a polystyrene matrix. Recently, high ordered nano-phase segregation of block copolymers (BCP) were obtained by microwave annealing. A few minutes of irradiation were sufficient to organize polystyrene or poly(methyl methacrylate) based copolymer in lamellae, cylinders or 
spheres.[30-33] Buriak et al. have proved that highly resistant silicon substrates (1-35 Ohms, doped by boron) can reach $200^{\circ} \mathrm{C}$ in a few seconds and serve as a hot pan to induce the nanosegregation of $\mathrm{BCP}$. [34, 35] On the contrary, when glass substrates were used, no morphological modification was detected to a significant extent.

In this study, we used the ultra-fast annealing induced by the microwave irradiation to promote the surface segregation of a diblock copolymer, a polystyrene-block-poly(pentafluorostyrene) (PS- $b$-PFS) at the air/polymer interface (Scheme 1). The BCP additive, has been engineered to present a PS block compatible with the polystyrene matrix and a PFS block bearing 5 surface active fluorine atoms per repetitive monomer units, which can undergo the para-fluoro-thiol click reaction. To the best of our knowledge, nothing has been reported on the surface segregation of pentafluorostyrene-based copolymers. Contact angle (CA) measurement, X-ray photoelectron spectroscopy (XPS) and Time-of-Flight Secondary Ion Mass Spectrometry (ToF-SIMS) analyses were carried out to demonstrate that a 60 seconds annealing is enough to enrich the surface of the blends with the BCP additive. Finally, the surface functionalization with gold nanoparticles GNPs was performed in two steps. Indeed, the successful nucleophilic substitution of the para fluorine atom with the thiol function of cysteine allows the immobilization of anchoring groups for GNPs surface docking. This proves the efficiency of surface segregation to create a functional platform from an inert substrate in a very short period of time and low energy consuming.
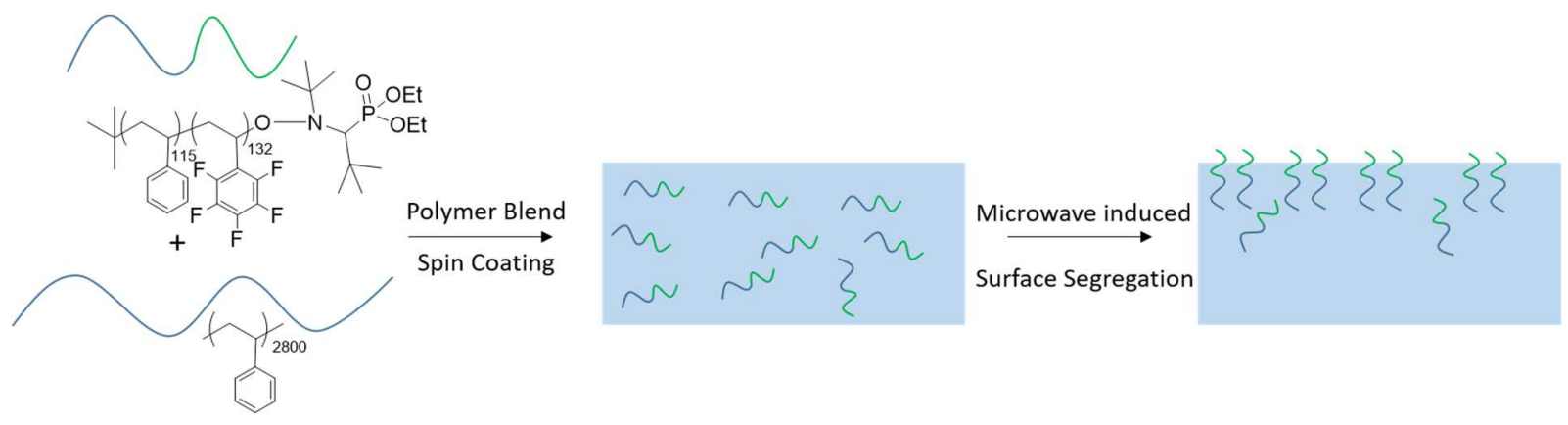

Scheme 1. Overview of the system studied in this report.

\section{Results and Discussion}

\subsection{PS- $b$-PFS copolymer synthesis}


The polystyrene-block-poly(pentafluorostyrene) (PS-b-PFS) was synthesized by Nitroxide Mediated Polymerization (NMP), a controlled radical polymerization based on the reversible trap of growing chains by nitroxide molecules (see in supporting information Scheme SI1).[36] The first step is the polymerization of styrene using the BlockBuilder ${ }^{\circledR}$ MA. Size exclusion chromatography was used to measure the molar mass of the polymer, $M n=12000 \mathrm{~g} \cdot \mathrm{mol}^{-1}$ (using conventional calibration with polystyrene sample), the average degree of polymerization $D P n=115$ and its dispersity, $Ð=1.27$. After purification, the PS was used as macroinitiator to polymerize pentafluorostyrene and access the block copolymer additive. To ensure a sufficient mixing with the PS matrix and a high amount of fluorine moieties, we targeted a copolymer with a balanced composition, presenting the two blocks length equal. ${ }^{1} \mathrm{H}$ NMR was used to evaluate the ratio between PS and PFS molecular units and a DPn of 132 was calculated for the PFS block (Figure SI1). SEC analysis of the PS- $b$-PFS revealed a shift in the molar mass compared to the PS macroinitiator (Figure SI2), meaning the efficient chain extension of the PS first block with a PFS block. The copolymer dispersity $Ð$ and molar mass $M n$ were calculated to be 1.15 and 38000 g.mol ${ }^{-1}$ respectively. Literature has shown that the segregation was best occurring when the additive had a smaller molar mass than the matrix, therefore we followed this requirement (PS matrix molar mass is 300,000 g.mol $\left.{ }^{-1}\right) \cdot[22,28]$ Differential Scanning Calorimetry was performed and only one glass transition temperature was detected at $107^{\circ} \mathrm{C}$ (Figure SI3) corresponding to the literature values of both PS and PFS homologue blocks.[37]

\subsection{Surface segregation}

2.2.1. Determination of suitable annealing conditions.

Films (thickness around $300 \mathrm{~nm}$ ) were prepared onto silicon wafers by spin-coating from toluene solutions (4\%) of a polymer blend composed of a PS matrix $\left(M n=300000 \mathrm{~g} \cdot \mathrm{mol}^{-1}, Ð=1.2\right)$ and the PS- $b$-PFS additive with a mass ratio 90/10. This first ratio was chosen to keep the additive content low and based on literature, which reports efficient segregation and surface properties evolution at $10 \%$ of additive.[17, 22, 26, 27] Such thick films were employed for two main reasons: 1) to avoid dewetting problems that appear in thin fluorine polymer films and 2) to separate the substrate/polymer and the polymer/air interfaces in order to reduce the number of competing interactions that can alter the surface segregation phenomenon.[13] Then, the films were introduced in a pressure resistant glass vial with air atmosphere (Figure SI4) and placed in the microwave oven. The optimal annealing 
conditions were determined by applying different irradiation powers during different times. XPS was the technique of choice to investigate the presence and the amount of fluorine atoms at the surface of the polymer films. Figure 1 presents the Carbon spectra of the non-annealed film and films treated with microwave at various powers $(10,20,30$ and 40 Watts $)$ during 60 seconds. Four major components are clearly observed: $\mathrm{C}=\mathrm{C}$ from polystyrene rings $(\mathrm{sp} 2,284.5 \mathrm{eV}), \mathrm{C}-\mathrm{C}$ from vinylic bonds of polystyrene (sp3, $285 \mathrm{eV}), \mathrm{C}-\mathrm{F}$ from polypentafluorostyrene rings $(288.5 \mathrm{eV})$ and the remaining 3 carbons of the pentafluorostyrene units 286.2 eV).[37, 38] The $\pi-\pi^{*}$ shake-up transitions of both polystyrene and polypentafluorostyrene are also observed at $291 \mathrm{eV}$ and 293-296 eV, respectively. Quantitative analysis of the non-annealed film shows that the intensities ratio of the $\mathrm{C}=\mathrm{C}(68.1 \%)$ and $\mathrm{C}-\mathrm{C}(23.5 \%)$ components agrees with the composition of polystyrene (6:2). Note that the C-C component at $285 \mathrm{eV}$ could also include aliphatic carbon from contamination. The polypentafluorostyrene is best fitted with two components (intensity ratio 5:3): $5 \mathrm{C}-\mathrm{F}$ bounds from the aromatic ring and the remaining 3 other carbons (those in the chain backbone) whose electrons are withdrawn by the fluorine atoms.[39]

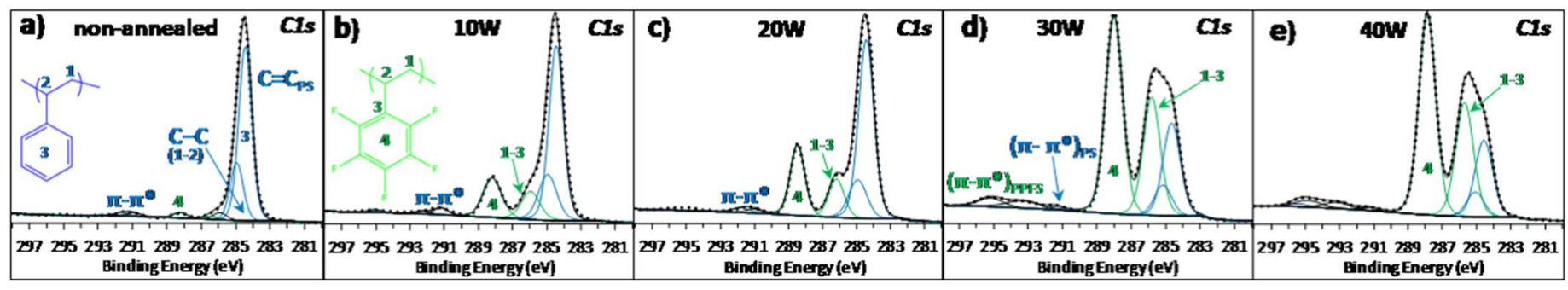

Figure 1. XPS carbon spectra of the a) non-annealed film and films treated with microwave at various powers: $10 \mathrm{~b}), 20 \mathrm{c}), 30 \mathrm{~d})$ and $40 \mathrm{~W}$ e) during 60 seconds.

As reported in Table 1, the intensity of fluorine increases along with the annealing power. A very significant increase is observed between the non-annealed sample (F: $3.8 \%)$ and the sample annealed at $10 \mathrm{~W}$, the minimum annealing power (F: $12.3 \%)$. When the annealing power is increased from $10 \mathrm{~W}$ to $30 \mathrm{~W}$, the intensity of the fluorine peak raises significantly to F: $26.8 \%$ (Figure 1b-d). When the annealing power is increased beyond 30 W, no further rise of the fluorine is observed. Indeed, the amount of fluorine detected in the sample annealed at $40 \mathrm{~W}$ (F: $28.5 \%$, Figure 1e) is close to the one in the sample annealed at $30 \mathrm{~W}$ (Table 1). Also, when the samples 
are annealed with different power conditions, from $10 \mathrm{~W}$ to $40 \mathrm{~W}$, no additional components are observed by XPS analysis. Only the intensities of the same former components change or increase. This suggests that there is no chemical degradation of the sample under those various conditions.

Table 1. XPS quantification and characterization of the film components in function of the power (annealing time $=60 \mathrm{~s})$.

\begin{tabular}{cccccccc}
\hline Components & $\begin{array}{c}\text { Position } \\
(\mathrm{eV})\end{array}$ & $\begin{array}{c}\text { FWHM } \\
(\mathrm{eV})\end{array}$ & $\begin{array}{c}0 \mathrm{~W}^{\mathrm{a}} \\
(\% \text { At. })\end{array}$ & $\begin{array}{c}10 \mathrm{~W} \\
(\% \text { At. })\end{array}$ & $\begin{array}{c}20 \mathrm{~W} \\
(\% \text { At. })\end{array}$ & $\begin{array}{c}30 \mathrm{~W} \\
(\% \text { At. })\end{array}$ & $\begin{array}{c}40 \mathrm{~W} \\
(\% \text { At. })\end{array}$ \\
\hline $\mathrm{C}=\mathrm{C}$ & 284.5 & 0.9 & 66.1 & 46.4 & 45.2 & 18.7 & 15.2 \\
$\mathrm{C}-\mathrm{C}$ & 285 & 0.9 & 22.2 & 17.6 & 13.9 & 8.4 & 6.8 \\
$\mathrm{C}-\mathrm{CF}$ & 286.2 & 1 & 2.1 & 8.7 & 8.9 & 16.7 & 17.8 \\
$\mathrm{C}-\mathrm{F}$ & 288.5 & 0.9 & 3.2 & 11.9 & 14.9 & 25.6 & 28.8 \\
$\pi-\pi^{*}$ & 292 & 1.2 & 2.6 & 3.1 & 2 & 3.8 & 2.9 \\
$\mathrm{~F}-\mathrm{C}$ & 688.7 & 1.4 & 3.8 & 12.3 & 15.1 & 26.8 & 28.5 \\
\hline
\end{tabular}

${ }^{a}$ Non-annealed sample

In order to save energy, $30 \mathrm{~W}$ was set as the optimum power to use in this study and the surface composition was followed during the annealing time from 0 to 210 seconds. Table 2 reports the carbon and fluorine surface content as measured by XPS (carbon spectra in Figure SI5). From 0 to 60 seconds microwave treatment, the fluorine surface content increases from 3.8 to $26.8 \%$, and then stays stable to $25.9 \%$ for 90 s. Finally, when the annealing is longer, 120 seconds, the fluorine content slightly decreases to $21.1 \%$. Although we could not observe a variation in the peaks shape in XPS, this decrease could come from a slight thermal degradation of the labile para-fluorine atoms at the interface with air.[35] This evolution in time corresponds to an increase of the temperature in the microwave vials. This leads consecutively to a more efficient surface segregation provided by a mobility rise and afterwards to a saturation at the surface. From these preliminaries experiments, a $60 \mathrm{~s}$ microwave treatment at $30 \mathrm{~W}$ was set for the rest of the study.

Table 2. XPS quantification and characterization of the film components in function of the annealing time (power $=30 \mathrm{~W})$.

\begin{tabular}{cccccccc}
\hline \multirow{2}{*}{ Components } & $\begin{array}{c}\text { Position } \\
(\mathrm{eV})\end{array}$ & $\begin{array}{c}\text { FWHM } \\
(\mathrm{eV})\end{array}$ & $\begin{array}{c}\text { 0 second } \\
(\% \text { At. })\end{array}$ & $\begin{array}{c}30 \mathrm{~s} \\
(\% \mathrm{At} .)\end{array}$ & $\begin{array}{c}60 \mathrm{~s} \\
(\% \mathrm{At} .)\end{array}$ & $\begin{array}{c}90 \mathrm{~s} \\
(\% \mathrm{At} .)\end{array}$ & $\begin{array}{c}120 \mathrm{~s} \\
(\% \mathrm{At} .)\end{array}$ \\
\hline
\end{tabular}




\begin{tabular}{lccccccc}
\hline $\mathrm{C}=\mathrm{C}$ & 284.5 & 0.9 & 66.1 & 58.6 & 18.7 & 22.7 & 29.7 \\
$\mathrm{C}-\mathrm{C}$ & 285 & 0.9 & 22.2 & 20.6 & 8.4 & 8.9 & 12.4 \\
$\mathrm{C}-\mathrm{CF}$ & 286.1 & 1 & 2.1 & 3.4 & 16.7 & 13.3 & 13.4 \\
$\mathrm{C}-\mathrm{F}$ & 288.5 & 0.9 & 3.2 & 6.1 & 25.6 & 21.5 & 19.2 \\
$\pi-\pi^{*}$ & 292 & 1.2 & 2.6 & 4.6 & 3.8 & 3.7 & 4.2 \\
$\mathrm{~F}-\mathrm{C}$ & 688.7 & 1.4 & 3.8 & 6.7 & 26.8 & 25.9 & 21.1 \\
\hline
\end{tabular}

${ }^{a}$ Non-annealed sample

\subsubsection{Variation of copolymer content in the blend}

The blend composition was varied from 0 to $100 \%$ of diblock copolymer to evaluate its influence on the surface wettability. Surface segregation was promoted via the microwave annealing and measurement of the contact angle with different liquids was performed to calculate the impact of the surface segregation on the surface tension values. In Figure 2a, the water contact angle is plotted against the copolymer content for the selected microwave treatment and, for comparison, the values of the non-annealed film are reported. First, the water contact angle raised when the copolymer content in the blend was increased, due to the augmentation of low surface energy fluorine atoms in the film. It is worth noting that the difference between the contact angles (CA) of a non-annealed pure PS film $\left(90^{\circ}\right)$ and the one of a pure PS- $b$-PFS film $\left(101^{\circ} \mathrm{C}\right)$ is low. Nevertheless, after the microwave annealing, there is a clear increase in the water CA value for each composition of the blend except for the pure copolymer film. This is also in agreement with the surface segregation of the fluorinated segments observed by XPS. In the pure copolymer sample, the fluorine surface content before annealing must be sufficiently high to provide the surface with hydrophobic properties. The evolution of the contact angle with a non-polar solvent such as diiodomethane (Figure $2 \mathrm{~b}$ ) is more affected by the blend composition. Indeed, the difference between the pure polystyrene and the copolymer surface is $37^{\circ}$ (respectively $29^{\circ}$ and $66^{\circ}$ after annealing). The same behavior has been observed between polyethylene and poly(tetrafluoroethylene) in which contact angle with diodomethane varied from 52 to $88^{\circ} \mathrm{C}$ when water contact angle changed only from 94 to $108^{\circ}$.[40] It can also be observed in Figure $2 \mathrm{~b}$ that for every blend ratio above $5 \%$ in additive, an increase of $20^{\circ}$ is measured after the treatment of the film at $30 \mathrm{~W}$ during 60 seconds compared to the non-annealed sample. Oleophobic surfaces have largely been developed with polymer substrates and a common strategy is to functionalize micro-patterned surfaces with fluorine molecules.[41] Surface tension of the different polymer films was calculated by the OWRK method from the contact angle of three solvents, Water, Diiodomethane and Ethylene glycol (see experimental part and Table SI1 and SI2). Again, a strong influence of the surface segregation of the additive can be extracted from the values 
reported in Figure 2c. For the blend with 5, 10 and $20 \%$ in additive, the surface tension decreased by 4 to 8 $\mathrm{mN} . \mathrm{m}^{-1}$ after the microwave annealing. For comparison, the difference between polyethylene and poly(tetrafluoroethylene) surface tension is around $12 \mathrm{mN} / \mathrm{m}$.[40]
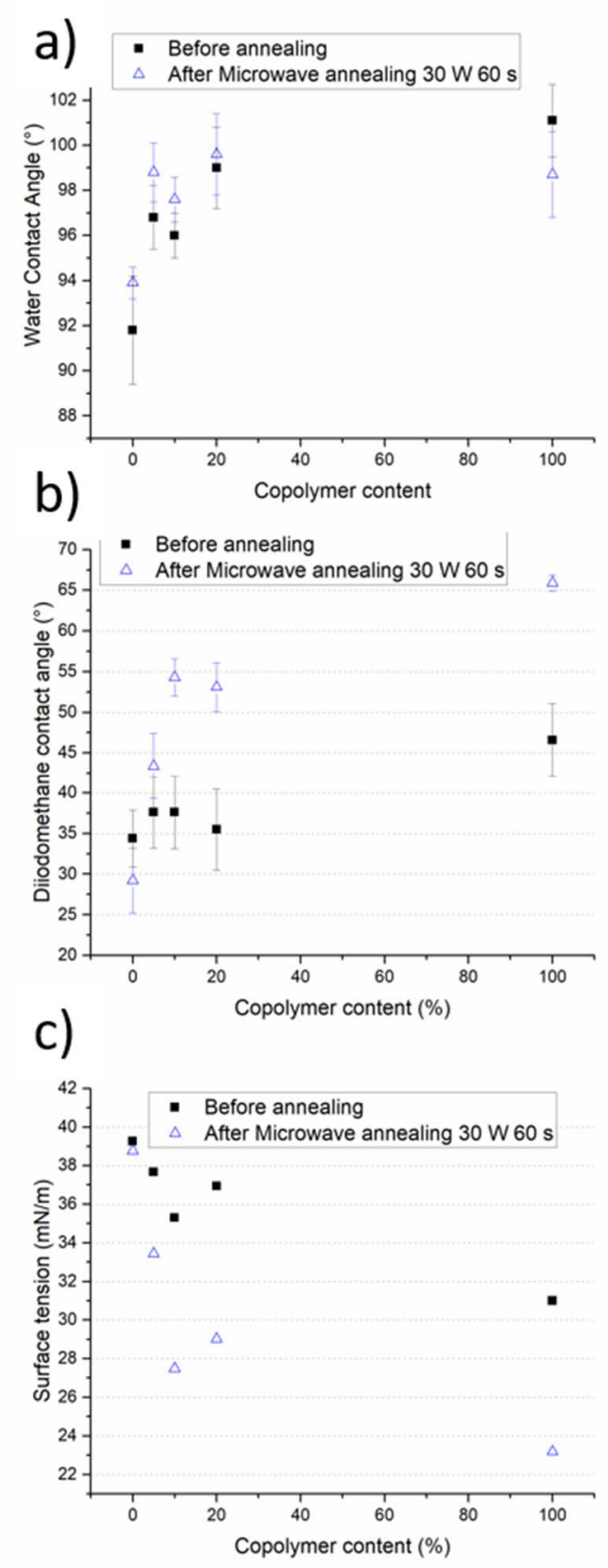

Figure 2. Evolution of the a) Water contact angle, b) Diiodomethane contact angle and c) surface tension of polymer blend composed of different matrix/additive ratios. 
In order to understand these changes of wettability, the surface composition of these blends was analyzed by XPS (carbon spectra in Figure SI6 and surface composition in Table SI3). Figure 3 presents the overlay of the surface fluorine content of polymer film before and after annealing, with the theoretical content in the blend calculated from the matrix/additive ratio (calculation described in SI). The first observation is that the value of the fluorine surface content just after spin-coating is higher that the theoretical one. This means that surface segregation happened even during the evaporation process.[42] Indeed, the solvent allows chains to reorganize in order to minimize surface tension. This effect has already been observed by Affrossman et al. when they reported the study of a blend composed of a polystyrene matrix with a fluorine end-functional polystyrene.[27] Secondly, for all the blend compositions, the fluorine surface content increases after the microwave annealing promoting the migration of the copolymer. For example, when a blend of $5 \mathrm{w} \%$ in copolymer is used, the fluorine surface content is $2.1 \%$ before annealing, and reaches $14 \%$ after the 60 seconds treatment. This value corresponds to a surface enrichment as high as $55 \mathrm{w} \%$ in block copolymer. From a blend composed of $10 \%$ of copolymer, a fluorine surface content similar to the one of a pure copolymer film was reached after annealing (around $25 \%$ ). Finally, the increase of the fluorine content for the pure PS- $b$-PFS film compared to the theory means that a reorganization in the upper layer occurs and leads to the surface orientation of the PFS block to the air.

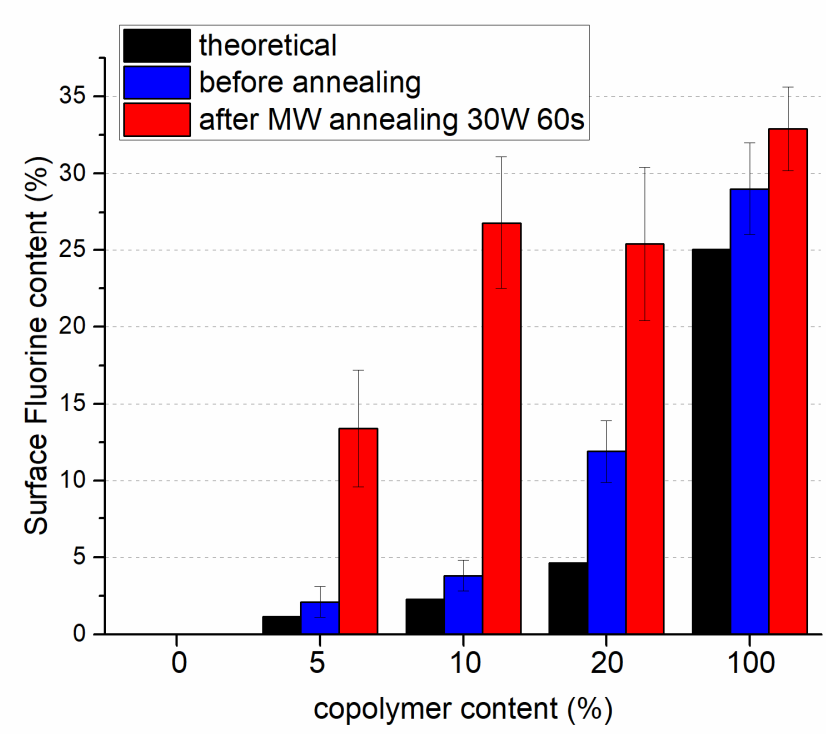

Figure 3. Comparison of the surface fluorine content determined by XPS before and after annealing for different polymer blends. The theoretical fluorine content in the blend is added, as calculated from the matrix/additive ratio. 
2.2.3. Reversible segregation upon annealing in humid environment

Tanaka and Koberstein have shown in two different studies that immersing a polymer blend in a polar environment (water or ethylene glycol) could induce the adsorption of the more hydrophilic component at the surface.[12, 43] Using a polystyrene terminated by a fluorinated group, they proved the surface depletion of fluorine atoms after an annealing in saturated water vapor at $55^{\circ} \mathrm{C}$ during 48 hours, resulting in the increase of the surface hydrophilicity. Indeed, the styrene unit being less hydrophobic than the fluorinated group, it migrated at the water/polymer interface. It has to be underlined that surface reorganization occurred in this case even in the glassy state. Following this finding, a sample composed of $10 \%$ of diblock was first subject to treatment in dry atmosphere at $30 \mathrm{~W}$ during $60 \mathrm{~s}$ and analyzed by XPS to monitor the evolution of the surface composition. The fluorine surface content was around $30 \%$ (see carbon spectra in Figure SI7 and surface composition in Table SI4). Then $0.5 \mathrm{~mL}$ of water was introduced at the bottom of the microwave vials, without changing the position of the samples (and the water does not touch the sample). Another annealing at $30 \mathrm{~W}$ during 60 seconds was applied and some water vapor was observed in the vial at the end of the treatment. The fluorine surface content detected by XPS then decreased to $11 \%$. The amount of fluorine for the sample annealed with water was still higher than before dry annealing $(2.8 \%)$ but lower than after the annealing in dry atmosphere $(30 \%)$. This strengthens previous findings in the literature in which research teams showed that annealing in water atmosphere could decrease the fluorine surface content of polystyrene blends. [12, 43, 44] Although the fluorine surface content didn't decrease to $0 \%$ after 60 seconds at $30 \mathrm{~W}$, an appropriate annealing could lead to pure polystyrene surface. The objective of this study being surface functionalization from the fluorostyrene moieties, we did not further investigate this point.

\subsubsection{Fluorine Depth Profile}

In order to obtain more informations on the in-depth spatial distribution of fluorine within the copolymer film depending on the annealing conditions, ToF-SIMS depth profiles experiments (series of 30 cycles "analysis/sputtering" with $10 \mathrm{sec}$ of etching per cycle) were performed on three different samples: a) the nonannealed film, b) the one after the microwave annealing in dry atmosphere (30W 60s) and c) the film after two 
consecutive annealings, one in dry atmosphere followed by one in water vapor (2 times (30W, 60s)). Figure 4 presents the concentration depth-profile of $\mathrm{C}_{2}^{-}$(in blue, representing the PS polymer matrix) and $\mathrm{F}^{-}$(in green, representing the PFS block of the BCP additive) secondary ions over 220 seconds etching time obtained in negative polarity for the samples a), b) and c). The signal intensities were normalized relative to the total ion counts and adjusted to allow a better comparison between the three systems. In all cases, the $\mathrm{C}_{2}^{-}$concentration increases with the etching while the $\mathrm{F}^{-}$one decreases. However, for the annealing in dry atmosphere, the $\mathrm{F}^{-}$signal decreases quickly at the beginning of the etching (the normalized intensity is equal to 0.07 after 5 cycles / $50 \mathrm{sec}$ ), while the $\mathrm{F}^{-}$signal intensity remains much higher through all the sputtering for the non-annealing sample (the normalized intensity is equal to 0.48 after $50 \mathrm{sec}$ and close to 0.4 at the end of the etching). For the sample c) with two consecutive annealing (one in dry atmosphere and one in water vapor), the fluorine signal mainly decreases during the five first cycles (the normalized intensity is equal to 0.16 after $50 \mathrm{sec}$ ) but with a lower slope comparing to sample b). Afterwards the intensity remains stable between $70 \mathrm{sec}$ and $140 \mathrm{sec}$ and then slightly increases to 0.2 until the end of the sputtering. A 3D image can be reconstructed for each system from the related depth profiles where the signal intensities of the considered secondary ions $\mathrm{C}_{2}{ }^{-}$and $\mathrm{F}^{-}$are plotted over the analyzed area $(600 \mu \mathrm{m} .600 \mu \mathrm{m}=\mathrm{x}$ and $\mathrm{y}$ dimensions) versus the etching time (the $\mathrm{z}$ axis, $220 \mathrm{~s})$. For a better visibility, the $\mathrm{Z}$ axis is over-dimensioned compared to the other axes. Each species has a 3D distribution over the analyzed volume with one specific color (blue for $\mathrm{C}_{2}{ }^{-}$and green for $\mathrm{F}^{-}$). The final 3D map corresponds to the overlay of the two species 3D distributions, to which a transparency factor is applied so that the two colors can be seen (the light blue color corresponds to areas where both ions $\mathrm{C}_{2}{ }^{-}$and $\mathrm{F}^{-}$are present). When a color (corresponding to one species) is not appearing anymore on the image, it means the intensity of the related peak on the mass spectrum is too low to be plotted. Note that the sputtered depth has not been determined here; references samples of each polymer with precise thickness should have been analyzed using the same etching conditions to determine the sputtering ion yield of each compound. The 3D image related to the annealing in dry atmosphere b) clearly shows that fluorine species, characteristic of the PFS block, are mainly located at the upper part of the sample, which confirms the enrichment of the surface blend by the BCP additive and the depletion of the inner layers (bulk). For the non-annealed film a), even if the proportion of $\mathrm{F}^{-}$is higher at the top surface than in the inner part of the blend, fluorine species are observed all over the analyzed volume, which confirms that $\mathrm{BCP}$ additive is present everywhere in the blend before annealing. Regarding the sample c), fluorine species are mainly located at the 
surface of the blend but also over the entire analyzed volume, which reveals a fluorine migration from the top to the inner part of the blend induced by the second annealing in wet atmosphere. This preliminary experiment highlights the reversibility of the segregation process by changing the conditions of annealing.
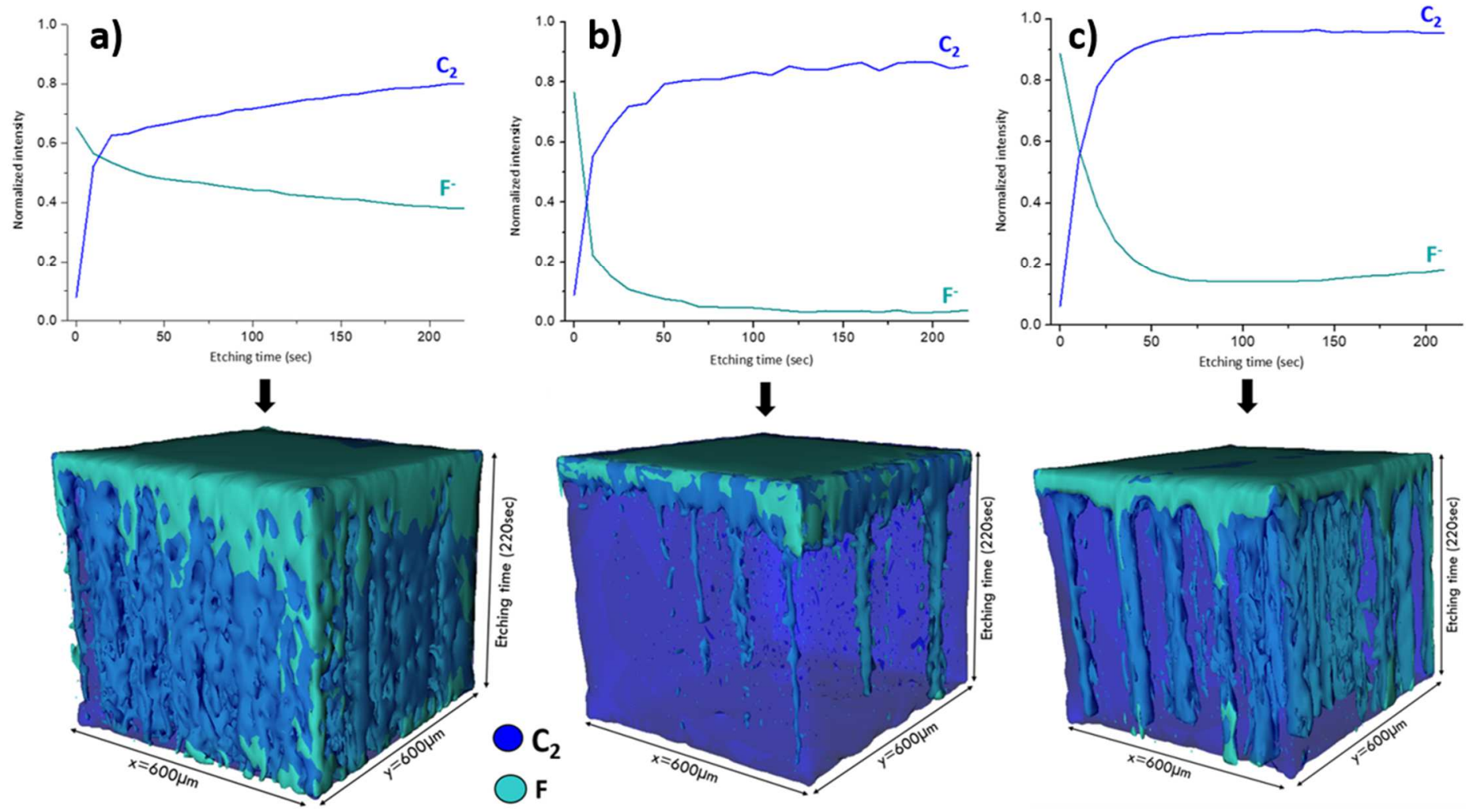

Figure 4. TOF-SIMS depth-profile experiments over 220s etching time of $\mathrm{C}_{2}^{-}$(in blue) and $\mathrm{F}^{-}$(in green) secondary ions in negative polarity and 3D images reconstruction from the depth-profiles showing the spatial distribution over $600.600 \mu \mathrm{m}^{2}$ raster size and 220 s etching time (for a better visibility, the $\mathrm{z}$ axis is overdimensioned compared to the other axes) of $\mathrm{C}_{2}^{-}$(in blue) and $\mathrm{F}^{-}$(in green) at the surface of a polymer film from a blend of 10/90 in block copolymer/PS matrix a) before annealing, b) after a microwave annealing in air at 30W during 60s, c) after 2 successive microwave annealings at $30 \mathrm{~W}$ during $60 \mathrm{~s}$, the first one in air and the second one in humid atmosphere.

\subsection{Surface para-fluoro-thiol click reaction}

In 2017, Delaittre et al. synthesized a statistical copolymer of N,N-dimethylacrylamide and pentafluorostyrene and studied its modification with thiols in water.[45] Following their experimental procedure, we studied the surface functionalization of the polystyrene film. For that purpose, a polymer blend composed of $10 \mathrm{w} \%$ of PS- 
$b$-PFS was submitted to the microwave annealing to reveal the pentafluorostyrene moieties at the surface. Then, cysteine was grafted via thiol nucleophilic substitution of the para-fluorine atoms (Figure 5). XPS analysis of the annealed film grafted with cysteine revealed the presence of the anchored molecule at the surface of the sample, with nitrogen and sulfur atoms detection. The amount of fluorine measured by XPS after the modification decreased significantly $(17.1 \%$, Table SI5) as compared with the film before the cysteine grafting $(29.8 \%)$. This is mainly due to the nucleophilic substitution of the para-fluorine atom. However, if only one fluorine (in para position) out of five in the repetitive unit is substituted by cysteine, then $24 \%$ out of the initial $30 \%$ of fluorine must remain at the surface. The extra $7 \%$ (from 24 to $17 \%$ ) can either come from the presence of additional chemical elements at the surface of the film (sulfur, nitrogen) that naturally decreases the atomic composition of all element, or from a possible slight reorganization of the surface during the grafting reaction occurring in water (at room temperature), leading to a decrease in the PSF surface content. Therefore, it was not possible to investigate precisely the amount of fluorine that reacted with cysteine.

After the immobilization of gold nanoparticles via the cysteine anchors, no changes were observed by XPS in the chemical environments of the various elements. Only the grafted GNPs were clearly detected with a significant atomic contribution of $1.1 \%$ (Table SI5).
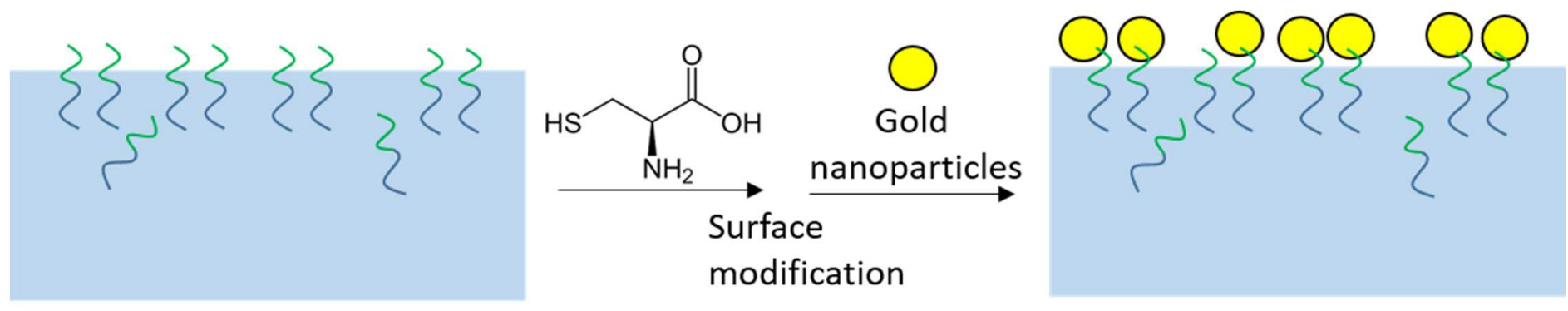

Figure 5: Gold nanoparticles grafting onto the pentafluorostyrene platform revealed by surface segregation

Atomic force microscopy was also used to assess the changes of the surface morphology before and after microwave annealing but also after GNPs grafting. In the PS- $b$-PFS block copolymer, the PS volume fraction is 0.4 and the AFM analysis of the pure diblock showed a nano-phase segregation with a mixture of in-plane and out of plane PS cylinders in a PFS matrix (see Figure SI8a). Figure 6a shows the image of the polymer blend with 
$10 \%$ of diblock before microwave treatment. The surface is mainly covered by polystyrene (in yellow) with small copolymer domains (corresponding to black domains). After microwave annealing, the surface covered by the copolymer largely increased and $200 \mathrm{~nm}$ domains appeared in which an out-of-plane cylindrical nano-structure can be observed (Figure 6b). Around these large domains, the homopolystyrene matrix is pierced by smaller copolymers areas. Obviously, the PS matrix does not swell the PS domain of the diblock due to its high molar mass $\left(\approx 300000\right.$ g. $\left.\mathrm{mol}^{-1}\right)$ but there is a good compatibility between the macromolecules since no microphase segregation was observed. After the GNPs grafting, the films were imaged by AFM and SEM (Figure 6c and 6d respectively). With both techniques, a non-uniform gold pattern is observed, with a structure corresponding to the PS- $b$-PFS initial domains. Indeed, the PS phases being insensitive to nucleophilic substitution, the nanoparticles cannot be immobilized in these areas. It has to be underlined here, that the geometry of the grafting area (cylinders) is dependent of the diblock composition and therefore can be tuned by appropriate synthesis conditions. The average diameter of gold nanoparticles measured from AFM images (Figure 6-c) is $25 \mathrm{~nm}$ in good correlation with the UV-visible absorbance spectrum of the unbound particles showing a maximum at 523 $\mathrm{nm}$ (figure SI15). 

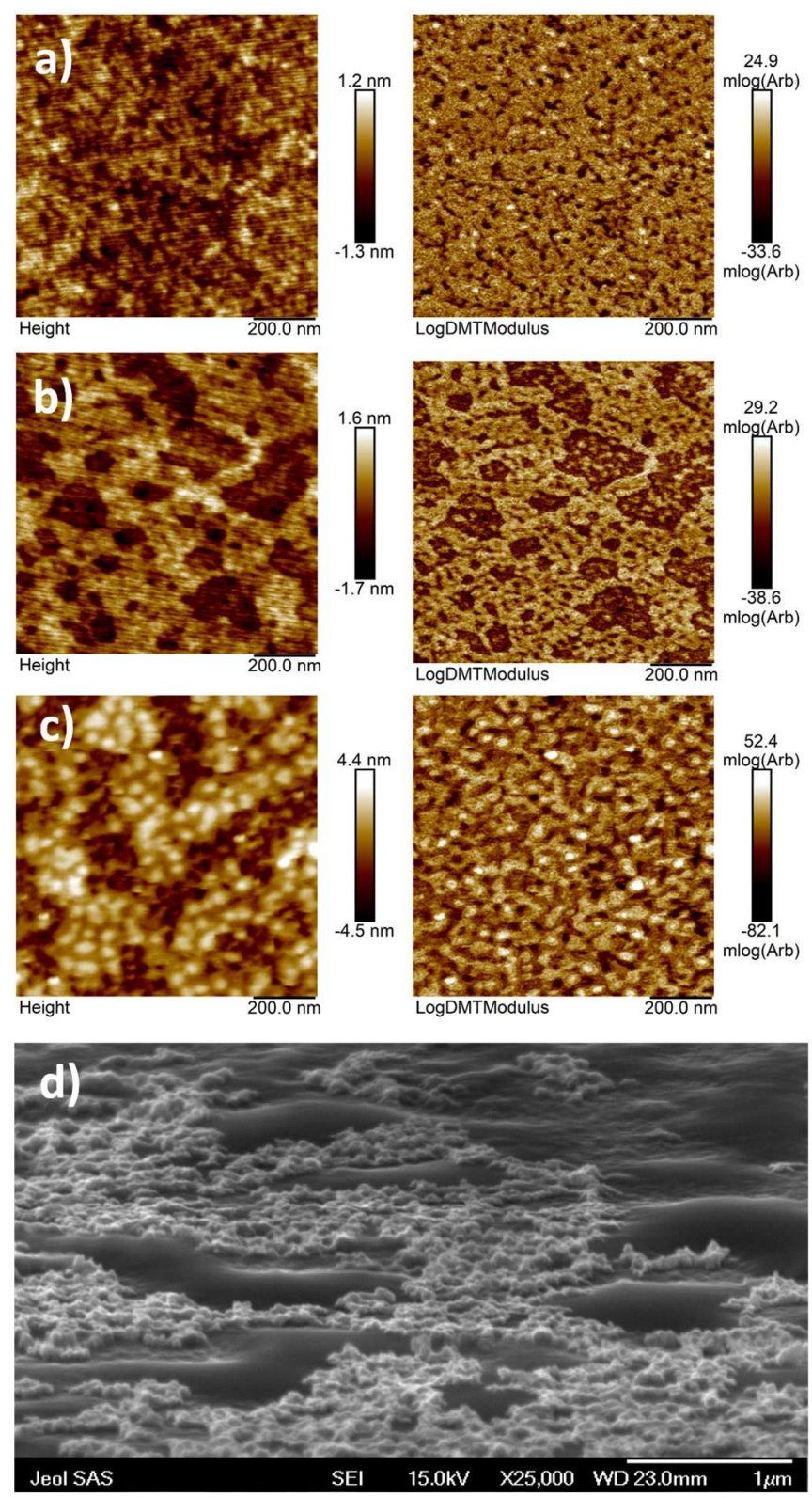

Figure 6. Images of the surface of a blend composed of $10 \%$ PS- $b$-PFS a) before any modification (AFM), b) after microwave annealing (AFM) c),d) after functionalization with Au NPs (AFM c, SEM d).

\section{Conclusion}

In summary, we demonstrated the efficiency of a microwave annealing to promote the surface segregation of a fluorinated additive, the PS- $b$-PFS, in a PS matrix. In 60 seconds, at a power of $30 \mathrm{~W}$, the block copolymer enriches the surface and increases the hydrophobicity and oleophobicity of the film, without degradation of the matrix material. A blend of $10 \mathrm{w} \%$ in additive can lead to a surface composed of more than $20 \%$ of fluorine atoms. ToF-SIMS, used to follow the in-depth spatial distribution of fluorine within the film, clearly showed that the surface was enriched in copolymer compared to the bulk of the film. This surface segregation phenomenon 
is reversible. Indeed, when the same microwave annealing is performed under water vapor atmosphere, the low surface energy fluorine atoms hide in the bulk and a polystyrene surface is restored. Finally, it was proved that this time and energy reducing methodology is an efficient way to provide a functional platform for the immobilization of materials at the surface of, at the beginning, inert (PS) materials. Indeed, the PFS moieties can undergo nucleophilic substitution with thiol and have been used in this study to immobilize GNPs in the block copolymer domains. This methodology could be applied to a wide range of applications such as supported catalysis or bioadhesion.

\section{METHODS}

\subsection{Experimental}

\section{Synthesis}

PS- $b$-PFS diblock copolymer was synthesized in two steps using Nitroxide-Mediated Polymerization (NMP) as reported in supporting information (Scheme SI1). In the first step, styrene (120 mmol), the Blocbuilder® alkoxyamine $(0.5 \mathrm{mmol})$ and the nitroxide radical (SG1 solution, $0.07 \mathrm{mmol}, 15 \%)$ were added to a round bottom flask of $50 \mathrm{~mL}$. The flask was sealed with a septum, put in an ice bath, degazed for fifteen minutes with nitrogen and immersed in an oil bath at $115{ }^{\circ} \mathrm{C}$ for $5 \mathrm{~h}$ to reach $50 \%$ of conversion (determined by ${ }^{1} \mathrm{H}$ NMR). The resulting viscous mixture of polystyrene (PS) and the styrene were precipitated twice in methanol to remove the remaining monomer, filtered and dried at room temperature under vacuum. In the last step, $300 \mathrm{mg}$ of the dried powder of PS (0.025 mmol) were dissolved in $5 \mathrm{~mL}$ of dimethylformamide (DMF) overnight. After solubilizing PS-macroinitiator, the $50 \mathrm{~mL}$ round bottom flask was put in an ice bath. Then pentafluorostyrene (PFS) $(7.5 \mathrm{mmol})$ and nitroxide radical (SG1 solution, $0.003 \mathrm{mmol}, 15 \%)$ were added, the flask was sealed with a septum and the mixture was degassed for 15 minutes with nitrogen and immersed in an oil bath at $115^{\circ} \mathrm{C}$. After 3h, the reaction was stopped and the resulting block copolymer was precipitated twice in methanol, filtered, and dried at room temperature under vacuum. The resulting block copolymer (PS- $b$-PFS) was analyzed by ${ }^{1} \mathrm{H}$ NMR and size exclusion chromatography (SEC).

The homopolystyrene matrix is a commercial product from PSS-Polymer with a molar mass of $\mathrm{Mn}=300$ $000 \mathrm{~g} \cdot \mathrm{mol}^{-1}$ and $\mathrm{a} \doteq=1.2$. 


\section{Surface attachment of gold nanoparticles}

The attachment of gold nanoparticles at the surface of the polymer blend with $10 \%$ of diblock after microwave treatment was done through a nucleophilic substitution of the pentafluorostyrene with thiol groups from the cysteine. A $4 \%$ toluene solution of polymer blend was spun cast on a silicon wafer substrate and annealed at 30 $\mathrm{W}$ during $60 \mathrm{~s}$ to allow the migration of the fluorine atoms at the surface of the film. The substrate was then dipped into $25 \mathrm{~mL}$ of a buffered solution ( $\mathrm{pH}$ 12: $\mathrm{NaOH}: 35 \mathrm{mg}+\mathrm{Na}_{2} \mathrm{HPO}_{4}: 115.4 \mathrm{mg}$ ) containing cysteine $(0.01 \mathrm{M})$ for 7 hours at room temperature to allow the grafting of cysteine via thiol nucleophilic substitution of the para-fluorine atoms. Afterwards the film was thoroughly washed several times in buffered solutions (pH 12) to remove unbound cysteine, and finally washed twice in water to remove and avoid the formation of salt crystals during the drying process. During all these steps, we didn't observe any degradation of delamination of the films. The film was dried and analysis by XPS to observe the attachment of cysteine at the surface of the annealed film. A decrease was also observed in the water contact angle value of the film, from $98^{\circ}$ to $72^{\circ}$ before and after cysteine grafting respectively. In the last step, the cysteine-grafted film was dipped again into $25 \mathrm{~mL}$ of a buffered solution containing cysteine $(0.01 \mathrm{M})$. Next $0.5 \mathrm{~mL}$ of a $50 \mathrm{mM}$ of $\mathrm{HAuCl}_{4}$ solution was added and mixed for 15 minutes before adding $2.5 \mathrm{~mL}$ of a $\mathrm{NaBH}_{4}$ solution $(0.01 \mathrm{M})$. After 2 hours, the color of the mixture became red due to the formation of gold nanoparticles stabilized by the fixation of cysteine at the surface of gold. This fixation occurs not only in solution but also at the film surface where cysteine molecules grafted on the film bound the surface of gold during the formation of the nanoparticles. The reaction was left over night at room temperature to complete the fixation of gold nanoparticles at the surface of the film. The film was washed successively in a buffered solution ( $\mathrm{pH}$ 12) and in water several times to remove unbound nanoparticles and avoid the formation of salt crystals.

\section{Thin films preparation}

Toluene solutions of polymer blend were prepared at $4 \mathrm{w} \%$ and spin-coated onto boron doped silicon substrates (TED PELLA - prod. $\mathrm{n}^{\circ} 16010$, Orientation: <100>, Resistance: 1-30 Ohms Type: P (Boron doped)) at $1000 \mathrm{rpm}$ to reach a thickness around $300 \mathrm{~nm}$ (measured by ellipsometry). 
A CEM microwave was used on fixed mode at several powers for a controlled time. Microwave heating films were cast on substrate with a surface of $0,7 \times 0,7 \mathrm{~cm}^{2}$. The set-up used to submit the wafers to the microwave irradiation is described in supporting information (SI1). For the experiments in humid atmosphere, $0.5 \mathrm{~mL}$ of water is added in the microwave tube at the bottom without any contact with the film.

\section{Characterization Techniques}

All details about the characterization techniques can be found in supporting information.

\section{Associated content}

Supporting Information. Experimental details and additional characterization data. This material is available free of charge via the Internet at http://pubs.acs.org.

\section{Author information}

Corresponding author: antoine.bousquet@univ-pau.fr

\section{Acknowledgements}

We acknowledge the government of Thailand and Doctoral School ED211 for PhD funding. ARKEMA is thanked for providing BlockBuider MA.

\section{References}

[1] S.K. Nemani, R.K. Annavarapu, B. Mohammadian, A. Raiyan, J. Heil, M.A. Haque, A. Abdelaal, H. Sojoudi, Surface Modification of Polymers: Methods and Applications, Advanced Materials Interfaces 5(24) (2018).

[2] Y. Ikada, Surface modification of polymers for medical applications, Biomaterials 15(10) (1994) 725-736.

[3] M. Behl, J. Seekamp, S. Zankovych, C.M.S. Torres, R. Zentel, J. Ahopelto, Towards plastic electronics: Patterning semiconducting polymers by nanoimprint lithography, Advanced Materials 14(8) (2002) 588-591.

[4] J.M. Goddard, J.H. Hotchkiss, Polymer surface modification for the attachment of bioactive compounds, Progress in Polymer Science (Oxford) 32(7) (2007) 698-725.

[5] J. Saqib, I.H. Aljundi, Membrane fouling and modification using surface treatment and layer-by-layer assembly of polyelectrolytes: State-of-the-art review, Journal of Water Process Engineering 11 (2016) 68-87.

[6] H. Nandivada, X. Jiang, J. Lahann, Click chemistry: Versatility and control in the hands of materials scientists, Advanced Materials 19(17) (2007) 2197-2208. 
[7] H. Gehan, L. Fillaud, M.M. Chehimi, J. Aubard, A. Hohenau, N. Felidj, C. Mangeney, Thermo-induced electromagnetic coupling in gold/polymer hybrid plasmonic structures probed by surface-enhanced raman scattering, ACS Nano 4(11) (2010) 6491-6500.

[8] O. Díaz Arado, H. Mönig, H. Wagner, J.H. Franke, G. Langewisch, P.A. Held, A. Studer, H. Fuchs, On-surface azide-alkyne cycloaddition on Au(111), ACS Nano 7(10) (2013) 8509-8515.

[9] R. Zandi Shafagh, A. Vastesson, W. Guo, W. Van Der Wijngaart, T. Haraldsson, E-Beam Nanostructuring and Direct Click Biofunctionalization of Thiol-Ene Resist, ACS Nano 12(10) (2018) 9940-9946.

[10] J. Li, J. Liang, L. Li, F. Ren, W. Hu, J. Li, S. Qi, Q. Pei, Healable capacitive touch screen sensors based on transparent composite electrodes comprising silver nanowires and a furan/maleimide diels-Alder cycloaddition polymer, ACS Nano 8(12) (2014) 12874-12882.

[11] G. Delaittre, L. Barner, The para-fluoro-thiol reaction as an efficient tool in polymer chemistry, Polymer Chemistry 9(20) (2018) 2679-2684.

[12] J.T. Koberstein, Molecular design of functional polymer surfaces, Journal of Polymer Science, Part B: Polymer Physics 42(16) (2004) 2942-2956.

[13] A. Bousquet, J. Rodriǵuez-Hernańdez, Nanostructured interfaces by surface segregation of block copolymers, Polymer Surfaces in Motion: Unconventional Patterning Methods2015, pp. 99-142.

[14] J. Genzer, K. Efimenko, Recent developments in superhydrophobic surfaces and their relevance to marine fouling: A review, Biofouling 22(5) (2006) 339-360.

[15] F. Liu, C.-H. Du, B.-K. Zhu, Y.-Y. Xu, Surface immobilization of polymer brushes onto porous poly(vinylidene fluoride) membrane by electron beam to improve the hydrophilicity and fouling resistance, Polymer 48(10) (2007) 2910-2918.

[16] J.T.J. Koberstein, D.E.D. Duch, W. Hu, T.J. Lenk, R. Bhatia, H.R. Brown, J.P. Lingelser, Y. Gallot, Creating Smart Polymer Surfaces with Selective Adhesion Properties, The Journal of Adhesion 66(1) (1998) 229 - 249.

[17] A. Bousquet, E. Ibarboure, C. Drummond, C. Labrugere, E. Papon, J. Rodriguez-Hernandez, Design of stimuliresponsive surfaces prepared by surface segregation of polypeptide-b-polystyrene diblock copolymers, Macromolecules 41(4) (2008) 1053-1056.

[18] C. Jalbert, J.T. Koberstein, A. Hariharan, S.K. Kumar, End group effects on surface properties of polymers: Semiempirical calculations and comparison to experimental surface tensions for $\alpha, \omega$-functional poly(dimethylsiloxanes), Macromolecules 30(15) (1997) 4481-4490.

[19] S.J. Hardman, L.R. Hutchings, N. Clarke, S.M. Kimani, L.L.E. Mears, E.F. Smith, J.R.P. Webster, R.L. Thompson, Surface modification of polyethylene with multi-end-functional polyethylene additives, Langmuir 28(11) (2012) 5125-5137.

[20] W.N.A. Bergius, L.R. Hutchings, N.M. Sarih, R.L. Thompson, M. Jeschke, R. Fisher, Synthesis and characterisation of end-functionalised poly( $\mathrm{N}$ - vinylpyrrolidone) additives by reversible addition-fragmentation transfer polymerisation, Polymer Chemistry 4(9) (2013) 2815-2827.

[21] Z. Su, D. Wu, S.L. Hsu, T.J. McCarthy, Adsorption of end-functionalized poly(ethylene oxide)s to the poly(ethylene oxide)-air interface, Macromolecules 30(4) (1997) 840-845.

[22] A. Bousquet, G. Pannier, E. Ibarboure, E. Papon, J. Rodriguez-Hernandez, Control of the surface properties in polymer blends, Journal of Adhesion 83(4) (2007) 335-349.

[23] A. Bousquet, R. Perrier-Cornet, E. Ibarboure, E. Papon, C. Labrugere, V. Heroguez, J. Rodriguez-Hernandez, Functional $\mathrm{pH}$-responsive polystyrene microspheres prepared by surface segregation of diblock copolymers, Macromolecules 40(26) (2007) 9549-9554.

[24] A. Bousquet, E. Ibarboure, C. Labrugere, E. Papon, J. Rodriguez-Hernandez, Structured assemblies of ferromagnetic particles through covalent immobilization on functionalized polymer surfaces obtained by surface segregation, Langmuir 23(13) (2007) 6879-6882.

[25] J.F. Elman, B.D. Johs, T.E. Long, J.T. Koberstein, A neutron reflectivity investigation of surface and interface segregation of polymer functional end groups, Macromolecules 27(19) (1994) 5341-5349.

[26] S. Affrossman, P. Bertrand, M. Hartshorne, T. Kiff, D. Leonard, R.A. Pethrick, R.W. Richards, Surface segregation in blends of polystyrene and perfluorohexane double end capped polystyrene studied by static SIMS, ISS, and XPS, Macromolecules 29(16) (1996) 5432-5437.

[27] S. Affrossman, J.M. Hartshorne, R.A. Pethrick, R.W. Richards, Surface Segregation in Blends of Hydrogenous Polystyrene and Perfluorohexane End-Capped Deuterated Polystyrene, Studied by SSIMS and XPS, Macromolecules 27 (1994) 1588-1591.

[28] R. Mason, C.A. Jalbert, P.A.V. O'Rourke Muisener, J.T. Koberstein, J.F. Elman, T.E. Long, B.Z. Gunesin, Surface energy and surface composition of end-fluorinated polystyrene, Advances in Colloid and Interface Science 94(1-3) (2001) 1-19.

[29] F. Xie, T. He, H.F. Zhang, F.K. Lee, B. Du, O.K.C. Tsui, Y. Yokoe, K. Tanaka, A. Takahara, T. Kajiyama, Effect of low surface energy chain ends on the glass transition temperature of polymer thin films, Macromolecules 35(5) (2002) 1491-1492. [30] X. Zhang, K.D. Harris, N.L.Y. Wu, J.N. Murphy, J.M. Buriak, Fast Assembly of Ordered Block Copolymer Nanostructures through Microwave Annealing, ACS Nano 4(11) (2010) 7021-7029. 
[31] P. Mokarian-Tabari, C. Cummins, S. Rasappa, C. Simao, C.M. Sotomayor Torres, J.D. Holmes, M.A. Morris, Study of the Kinetics and Mechanism of Rapid Self-Assembly in Block Copolymer Thin Films during Solvo-Microwave Annealing, Langmuir 30(35) (2014) 10728-10739.

[32] D.T.W. Toolan, K. Adlington, A. Isakova, A. Kalamiotis, P. Mokarian-Tabari, G. Dimitrakis, C. Dodds, T. Arnold, N.J. Terrill, W. Bras, D. Hermida Merino, P.D. Topham, D.J. Irvine, J.R. Howse, Selective molecular annealing: in situ small angle X-ray scattering study of microwave-assisted annealing of block copolymers, Physical Chemistry Chemical Physics 19(31) (2017) 20412-20419.

[33] D. Borah, R. Senthamaraikannan, S. Rasappa, B. Kosmala, J.D. Holmes, M.A. Morris, Swift nanopattern formation of PS- $b$-PMMA and PS- b -PDMS block copolymer films using a microwave assisted technique, ACS Nano 7(8) (2013) 65836596.

[34] C. Jin, J.N. Murphy, K.D. Harris, J.M. Buriak, Deconvoluting the Mechanism of Microwave Annealing of Block Copolymer Thin Films, ACS Nano 8(4) (2014) 3979-3991.

[35] N. Benoot, P. Marcasuzaa, L. Pessoni, S. Chasvised, S. Reynaud, A. Bousquet, L. Billon, Hierarchically organized honeycomb films through block copolymer directed self-assembly in "breath figure" templating and soft microwavetriggered annealing, Soft Matter 14(23) (2018) 4874-4880.

[36] C.J. Hawker, A.W. Bosman, E. Harth, New polymer synthesis by nitroxide mediated living radical polymerizations, Chemical Reviews 101(12) (2001) 3661-3688.

[37] G.D. Fu, Z. Yuan, E.T. Kang, K.G. Neoh, D.M. Lai, A.C.H. Huan, Nanoporous ultra-low-dielectric-constant fluoropolymer films via selective UV decomposition of poly(pentafluorostyrene)-block-poly(methyl methacrylate) copolymers prepared using atom transfer radical polymerization, Advanced Functional Materials 15(2) (2005) 315-322.

[38] L.M. Han, R.B. Timmons, W.W. Lee, Pulsed plasma polymerization of an aromatic perfluorocarbon monomer: Formation of low dielectric constant, high thermal stability films, Journal of Vacuum Science and Technology B: Microelectronics and Nanometer Structures 18(2) (2000) 799-804.

[39] S. Suzuki, M.R. Whittaker, E. Wentrup-Byrne, M.J. Monteiro, L. Grøndahl, Adsorption of Well-Defined FluorineContaining Polymers onto Poly(tetrafluoroethylene), Langmuir 24(22) (2008) 13075-13083.

[40] D.K. Owens, R.C. Wendt, Estimation of the surface free energy of polymers, Journal of Applied Polymer Science 13(8) (1969) 1741-1747.

[41] J. Yong, F. Chen, Q. Yang, J. Huo, X. Hou, Superoleophobic surfaces, Chemical Society Reviews 46(14) (2017) 41684217.

[42] J. Chen, H. Zhuang, J. Zhao, J.A. Gardella Jr, Solvent effects on polymer surface structure, Surface and Interface Analysis 31(8) (2001) 713-720.

[43] K. Tanaka, D. Kawaguchi, Y. Yokoe, T. Kajiyama, A. Takahara, S. Tasaki, Surface segregation of chain ends in $\alpha, \omega-$ fluoroalkyl-terminated polystyrenes films, Polymer 44(15) (2003) 4171-4177.

[44] D. Wong, C.A. Jalbert, P.A.V. Orourke-Muisener, J.T. Koberstein, Surface dynamics of polymer glasses: Sub- T g surface reorganization in end-functional polymers, Macromolecules 45(19) (2012) 7973-7984.

[45] H. Turgut, A.C. Schmidt, P. Wadhwani, A. Welle, R. Müller, G. Delaittre, The para-fluoro-thiol ligation in water, Polymer Chemistry 8(8) (2017) 1288-1293. 